\title{
Response of the Kuroshio Extension to Rossby Waves Associated with the 1970s Climate Regime Shift in a High-Resolution Ocean Model*
}

\author{
Bunmei Taguchi and Shang-Ping XIE + \\ Department of Meteorology, University of Hawaii at Manoa, Honolulu, Hawaii \\ Humio Mitsudera \\ Institute of Low Temperature Science, Hokkaido University, Sapporo, Japan \\ Atsushi KuboKawa \\ Graduate School of Environmental Earth Science, Hokkaido University, Sapporo, Japan
}

(Manuscript received 21 August 2004, in final form 31 January 2005)

\begin{abstract}
The response of the Kuroshio Extension (KE) to large-scale Rossby waves remotely excited by wind stress changes associated with the 1970s climate regime shift is studied using a high-resolution regional ocean model. Two ensemble simulations are conducted: The control run uses monthly climatological forcing while, in the second ensemble, anomalous forcing is imposed at the model eastern boundary around $165^{\circ} \mathrm{E}$ derived from a hindcast of decadal changes in subsurface temperature and salinity using a coarser-resolution model of the Pacific basin.

Near the KE, ocean adjustment deviates strongly from the linear Rossby wave dynamics. Most notably, the eastward acceleration of the KE is much narrower in meridional extent than that associated with the incoming Rossby waves imposed on the eastern boundary. This KE acceleration is associated with an enhanced potential vorticity (PV) gradient across the front that is consistent with the inertial western boundary layer theory: the arrival of the Rossby waves at the western boundary causes the eastward current to accelerate, leading to enhanced advection of low (high) PV water of subtropical (subarctic) origin along the western boundary layer. The meridional dipole of PV anomalies results in a pair of anomalous recirculations with a narrow eastward jet in between. A three-layer quasigeostrophic model is used to demonstrate this inertial adjustment mechanism. Finally, transient eddy activity increases significantly and the eddy momentum transport acts to strengthen the mean flow response. The result that ocean physical response to broad-scale atmospheric forcing is large near the KE front has important implications for fisheries research.
\end{abstract}

\section{Introduction}

The Kuroshio Extension (KE) or Kuroshio-Oyashio Extension (KOE) region exhibits the largest variability

\footnotetext{
* International Pacific Research Center Publication Number 315 and School of Ocean and Earth Science and Technology Publication Number 6557.
}

+ Additional affiliation: International Pacific Research Center, University of Hawaii at Manoa, Honolulu, Hawaii.

Corresponding author address: Bunmei Taguchi, Department of Meteorology, HIG360, University of Hawaii at Manoa, 2525 Correa Road, Honolulu, HI 96822.

E-mail: bunmei@hawaii.edu on both mesoscale and interannual time scales in the extratropical North Pacific Ocean (see Qiu 2002 for a review). It has come to be recognized as a region where ocean dynamics play an active role in low-frequency variations in sea surface temperature (SST) as demonstrated by recent observational (Qiu 2000; Tomita et al. 2002; Scott and Qiu 2003) and modeling (Xie et al. 2000; Schneider et al. 2002) studies. SST variations in this dynamic region affect local wind (Nonaka and Xie 2003) and heat flux (Tanimoto et al. 2003) at the sea surface, and may further influence the atmospheric storm track (Nakamura et al. 2004). Moreover, the KE's decadal/interdecadal variations affect some important fishery resources in the region (Sugimoto et al. 2001; Noto and Yasuda 1999). 

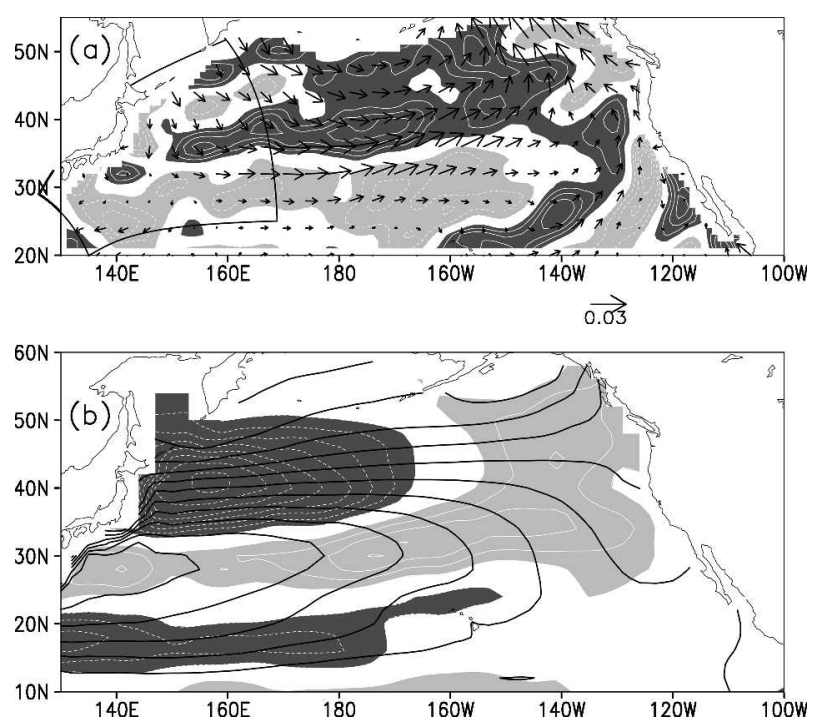

FIG. 1. (a) Decadal change in wind stress (vectors; $\mathrm{N} \mathrm{m}^{-2}$ ) and Ekman pumping velocity (dark shading: $>1 \times 10^{-7} \mathrm{~m} \mathrm{~s}^{-1}$; light shading: $<-1 \times 10^{-7} \mathrm{~m} \mathrm{~s}^{-1}$ with contours at intervals of $1 \times 10^{-7}$ $\mathrm{m} \mathrm{s}^{-1}$ ) between the period 1966-75 and the period 1976-85 based on NCEP-NCAR reanalysis. The domain of the regional OGCM used in this study is also shown with a solid sector. (b) Decadal change in subsurface temperature at 400-m depth (light shading: $>0.1^{\circ} \mathrm{C}$; dark shading: $<-0.1^{\circ} \mathrm{C}$ with white contours at intervals of $0.1^{\circ} \mathrm{C}$ ) between the period $1972-78$ and the period $1979-90$ calculated from the basinwide coarse-resolution OGCM hindcast by Xie et al. (2000). Mean subsurface temperature at 400-m depth over both periods is shown in black contour with $1^{\circ} \mathrm{C}$ contour interval.

The climate regime shift in the mid-1970s has received much attention and is characterized by enhanced westerly winds over the central Pacific Ocean (Fig. 1a) associated with a deepened Aleutian low. Oceanic response to the wind change of the regime shift has been extensively studied (Deser et al. 1999; Xie et al. 2000; Seager et al. 2001; Miller et al. 1998). Deser et al. discussed a westward-intensified spatial structure in decadal-scale temperature change at 400-m depth and showed that it is consistent with the Sverdrup transport inferred from wind stress curl change. A 4-5-yr delay of the subsurface response to the wind forcing further supports that the linear baroclinic Rossby wave adjustment is the primary mechanism for the westward-intensified thremocline change (Schneider and Miller 2001). The westward-intensified structure and the time delay in the thermocline response are reproduced in hindcast experiments using ocean general circulation models (OGCMs) (Miller et al. 1998; Xie et al. 2000; Seager et al. 2001).

Despite the success of the Rossby wave theory to explain the large-scale features of the oceanic response to wind changes, it is interesting to note that observa- tional data or numerical models used in previous studies have rather too coarse horizontal resolutions to resolve sharp oceanic fronts in the region. For instance, the Xie et al. OGCM at $1^{\circ}$ resolution, which is the same or better than that of many other OGCMs used in North Pacific hindcasting, produces a rather broad KOE around $35^{\circ}-45^{\circ} \mathrm{N}$ (Fig. 1b). This contrasts with fine structures observed in the region such as a doublefrontal structure, with the subarctic and Kuroshio Extension fronts located along $40^{\circ} \mathrm{N}$ and $35^{\circ} \mathrm{N}$, respectively (Qu et al. 2001), and stationary meanders of the KE front near Japan (Mizuno and White 1983; Niiler et al. 2003).

Large low-frequecy SST variability is confined to these narrow oceanic frontal zones (Nakamura et al. 1997; Qiu 2000). Nakamura and Kazmin (2003) documented decadal fluctuations in the axial position and the strength of the North Pacific subarctic frontal zone (NP-SAFZ) based on satellite and ship measurements of SST. They reported a sharpening and northward shift of the NP-SAFZ in the early 1990s so that the KE and NP-SAFZ fronts were well separated from each other during that period. Qiu (2003) found that the intensity of the KE jet varies on slow time scales based on an analysis of 10-yr-long TOPEX/Poseidon (T/P) sea surface height (SSH) data. He succeeded in simulating large-scale SSH changes using a linear Rossby wave model forced by observed winds, but the skill of his hindcast is low near the KE front. This suggests the importance of nonlinear dynamics in the KOE adjustment to changing wind.

The present study investigates the response of the $\mathrm{KE}$ front to basin-scale wind changes in the North $\mathrm{Pa}-$ cific. Our primary interest is a qualitative understanding of dynamics (whether linear or nonlinear) relevant to the KE front adjustment rather than a realistic hindcast of the past ocean state. Specific questions we wish to address include the following: What is the meridional structure of the KE front response to large-scale Rossby waves remotely excited by the wind change, and how do oceanic fronts adjust? Is the linear Rossby wave theory sufficient to explain the response? If not, what are the nonlinear mechanisms for the frontal response? Using a high-resolution regional OGCM that reproduces the subarctic front and KE front quite realistically, we carry out experiments by imposing largescale temperature and salinity anomalies on the eastern boundary to mimic the Rossby waves forced by basinscale wind changes in the 1970s. The choice of a regional model is to allow ensemble experiments to separate the forced response from the ocean internal variability (see section $2 b$ ). The model adjustment to the large-scale baroclinic forcing turns out to be highly non- 
linear, characterized by the acceleration of the KE frontal jet at a meridional scale much smaller than that of the forcing.

The rest of the paper is organized as follows. Section 2 introduces the regional OGCM and describes the experimental design. Sections 3 and 4 present the model results, focusing on the transient and steady responses, respectively. Section 5 discusses the mechanisms for the model adjustment, while section 6 is a summary.

\section{Regional OGCM experiment}

\section{a. Model}

The regional OGCM used in this study is based on the Princeton Ocean Model (POM), which solves primitive equations with a turbulent closure scheme (Blumberg and Mellor 1983). The model is configured to cover the portion of the western North Pacific Ocean roughly from $20^{\circ}$ to $52^{\circ} \mathrm{N}, 125^{\circ}$ to $170^{\circ} \mathrm{E}$, as shown in Fig. 1. The model employs the horizontal curvilinear coordinate grids with varying spacing from $1 / 12$ to $1 / 6^{\circ}$, with high resolutions near Japan. There are 32 sigma levels in the vertical.

The control run uses monthly climatological forcing based on the Hellerman and Rosenstein (1983) wind stress and heat flux calculated from the Comprehensive Ocean-Atmospheric Data Set (COADS; Slutz et al. 1985). A weak restoring to the monthly Levitus (1982) climatology is applied to SST and surface salinity. The monthly Levitus data are also used for the restoring for temperature and salinity at the lateral open boundaries and in the Sea of Okhotsk. In addition to the thermal forcing, inflow/outflow volume transports are imposed at the lateral boundaries, which include a fixed Kuroshio inflow of $25 \mathrm{~Sv}\left(\mathrm{~Sv} \equiv 10^{6} \mathrm{~m}^{3} \mathrm{~s}^{-1}\right)$ through Tokara Strait at the western boundary and Oyashio inflow of 28 (18) Sv in winter season (the rest of the year) along the Kuril-Kamchatka Trench at the eastern boundary. The model is spun up for $20 \mathrm{yr}$ from the resting Levitus climatology, and the output for the first $10 \mathrm{yr}$ is discarded.

Figure 2 shows the mean SSH climatology based on the last 10-yr integration. The model captures the salient features of the KE, such as the narrow strong Kuroshio taking a straight path (Kawabe 1995) south of Japan, its separation from the coast of Japan at about $35^{\circ} \mathrm{N}$, and a sharp KE front and its quasi-stationary meanders along $34^{\circ} \mathrm{N}$. Two prominent meanders around $144^{\circ}$ and $150^{\circ} \mathrm{E}$ are consistent with observations (Mizuno and White 1983; Niiler et al. 2003).

The model has been successfully used for studying the Oyashio water pathway in the KOE region (Mitsudera et al. 2004) and the interaction of mesoscale

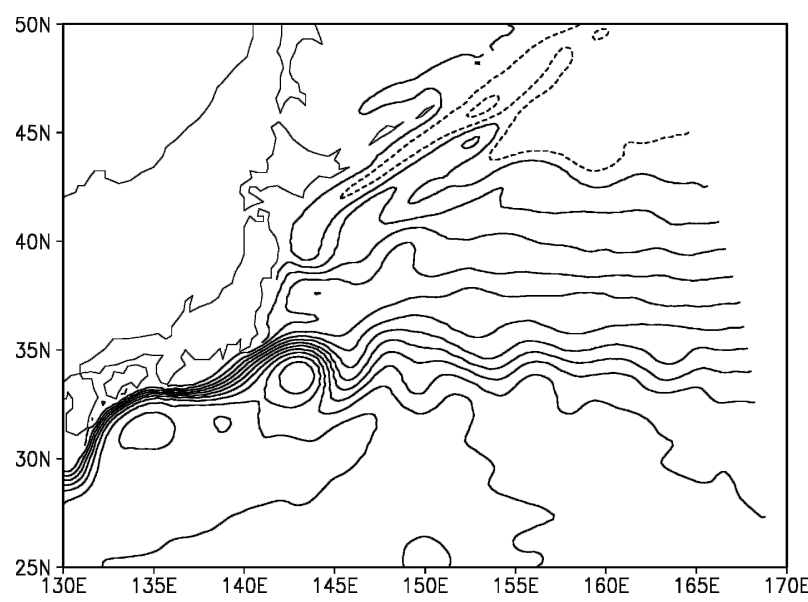

FIG. 2. Mean SSH field averaged over the last $10 \mathrm{yr}$ of a 20 -yr regional model control experiment. Contour interval is $0.1 \mathrm{~m}$. Contours with negative values are shown with dashed lines.

eddies and meandering Kuroshio south of Japan (Mitsudera et al. 2001; Waseda et al. 2002, 2003). Details about the model configuration and its performance may be found in Mitsudera et al. (2004).

\section{b. Experiment design}

From the end of the 10th year of the above 20-yr integration, we conduct two sets of ensemble simulations. In the control run, the model is driven with monthly climatological forcing as described above. In the other ensemble simulation, we impose anomalous lateral forcing at the model's eastern boundary (forced run hereafter), which is assumed to be caused by basinscale wind changes. We neglect both local wind stress changes over the model domain and the volume transport change at the eastern boundary due to the barotropic response to the wind forcing. Furthermore, the anomalous baroclinic forcing is kept constant in time at the lateral boundary, once switched on, since we are interested in ocean adjustment on decadal and longer time scales. We employ these simplifications of the numerical experiment to isolate the KOE response to incoming baroclinic Rossby waves.

The anomalous lateral forcing for the regional model is derived from the hindcast of the coarse-resolution North Pacific basin OGCM of Xie et al. (2000). Figure 3 depicts decadal temperature anomalies at $165^{\circ} \mathrm{E}$ near the eastern boundary of the regional model, obtained by subtracting December-February mean during the 1968-76 decade from that during 1977-88. These two decades are chosen based on the leading principal component of observed 50-m temperature anomalies in the North Pacific (Deser et al. 1999). The subsurface temperature anomalies feature a dipole structure with warm and cold anomalies in the subtropical and sub- 


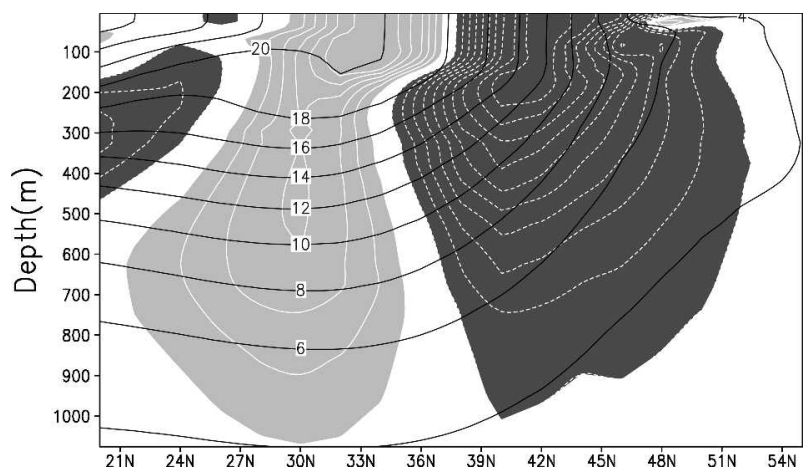

FIG. 3. Meridional cross section at $165^{\circ} \mathrm{E}$ of decadal change in temperature (light shading: $>0.1^{\circ} \mathrm{C}$; dark shading: $<-0.1^{\circ} \mathrm{C}$ with white contours at intervals of $0.1^{\circ} \mathrm{C}$ ) between the period $1968-76$ and the period 1977-88 calculated from the basinwide coarseresolution OGCM hindcast by Xie et al. (2000). Mean temperature averaged over both periods is shown in black contour with $1^{\circ} \mathrm{C}$ contour interval.

polar regions, respectively. These anomalies are the response of the basin OGCM to the decadal wind stress change east of $165^{\circ} \mathrm{E}$. Major anomalies are located in the model mean thermocline (black contours in Fig. 3), indicating that they are caused by the vertical displacement of the thermocline. In the western North Pacific, the ocean response to wind stress forcing is dominated by Rossby waves of the gravest barolinic mode, consistent with the observation (Deser et al. 1999) and previous numerical simulations (Miller et al. 1998; Xie et al. 2000). In the buffer zone near the model eastern boundary, these anomalies are added to the Levitus climatology to form the reference fields toward which the model temperature and salinity are restored. The subsurface density anomalies imposed at the eastern boundary of the model domain will excite baroclinic Rossby waves, and the rest of the paper investigates how the KE front responds to the incident Rossby waves. Mesoscale eddy activity is high in this highresolution regional model. To increase the signal-tonoise ratio and extract the forced response, we increase the anomalous temperature and salinity forcing on the eastern boundary by a factor of 3 . This exaggerates the lateral forcing, but not too much since the basin OGCM underestimates the subsurface anomalies by a factor of 2 compared to Deser et al.'s (1999) observations.

To separate the forced response from ocean internal variability, each ensemble consists of ten integrations with differing initial conditions prepared as follows. First, a model snapshot is separated into large-scale and mesoscale fields by taking the $10^{\circ}$ zonal running mean and subtracting it from the snapshot, respectively. Ten mesoscale-eddy fields are extracted from the snapshots at the end of the 11th to 20th years of the control spinup integration. Then, the resultant mesoscale fields are added to the large-scale field at the end of 10th-year control run to form the initial conditions for ensemble simulations. Thus, these 10 sets of initial conditions share the same large-scale field, free of biases in largescale fields that would result from model drift if the initial conditions were just the 31 December snapshots from the 11th to 20th model years. In the control ensemble, each integration lasts for $10 \mathrm{yr}$ using 1 of the 10 sets of initial conditions. The forced ensemble is the same as the control ensemble except that the eastern boundary forcing is switched on at the beginning and kept constant during the 10-yr integration. This initialvalue problem approach, while unrealistic, offers insights into forced ocean adjustment. The analysis of the solution after the model has reached a statistically steady state is useful for understanding the ocean response to slow-varying wind forcing on decadal and longer time scales.

\section{Transient response}

We first examine the transient response to the sudden onset of anomalous eastern boundary forcing. Figure 4 shows the evolution of ensemble and annual mean SSH differences between the control and the forced ensembles for the first $3 \mathrm{yr}$. Immediately after the lateral forcing is imposed, the geostrophic adjustment to the subsurface density anomalies quickly sets up meridional SSH gradients along the model eastern boundary (Fig. 4a). Then the anomalies on the eastern boundary propagate westward into the model interior as baroclinic Rossby waves, filling the model domain by the end of the third year (Figs. 4b,c). Figure 5 shows longitude-time sections of ensemble mean SSH difference at $29^{\circ}$ and $39^{\circ} \mathrm{N}$-latitudes that cut through the centers of the dipole SSH anomalies south and north of the KE, respectively. Phase speeds of the westward propagating signals are $0.021 \mathrm{~m} \mathrm{~s}^{-1}$ at $39^{\circ} \mathrm{N}$ and $0.053 \mathrm{~m} \mathrm{~s}^{-1}$ at $29^{\circ} \mathrm{N}$, as estimated from the constant phase lines in Fig. 5. These values are quite comparable to the phase speeds of the first baroclinic mode Rossby waves derived from T/P altimetry observations (Qiu 2003; Fu and Chelton 2001).

The transit time for the baroclinic waves to cross the model domain is about $2 \mathrm{yr}$ at $29^{\circ} \mathrm{N}$ and $2-3 \mathrm{yr}$ at $39^{\circ} \mathrm{N}$. Despite a slower phase speed at $39^{\circ} \mathrm{N}$ than at $29^{\circ} \mathrm{N}$, the transit times at both latitudes are almost the same because of a shorter distance from the model eastern boundary to the Japanese coast at $39^{\circ} \mathrm{N}$. Thus, we consider the model in a quasi-steady state for the last $5 \mathrm{yr}$ of integration. The westward propagation of the forced response is not uniform in the zonal direction. At $29^{\circ} \mathrm{N}$, the linear propagation may be traced up to $145^{\circ} \mathrm{E}$ and 
(a) ssh difference 11th

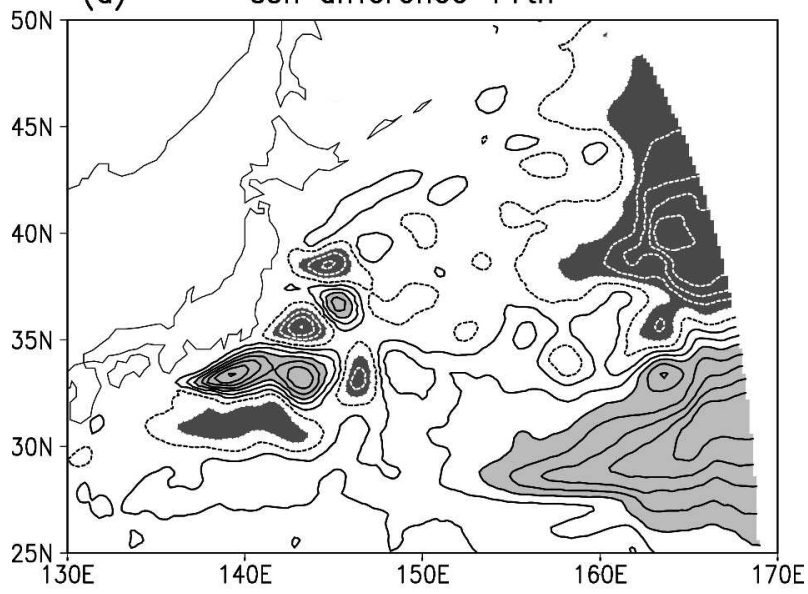

(b)

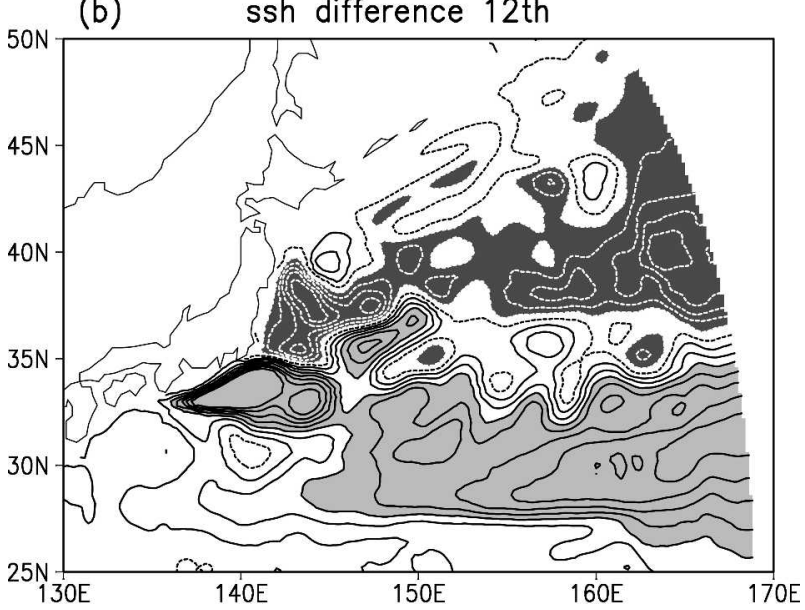

(c) ssh difference 13th

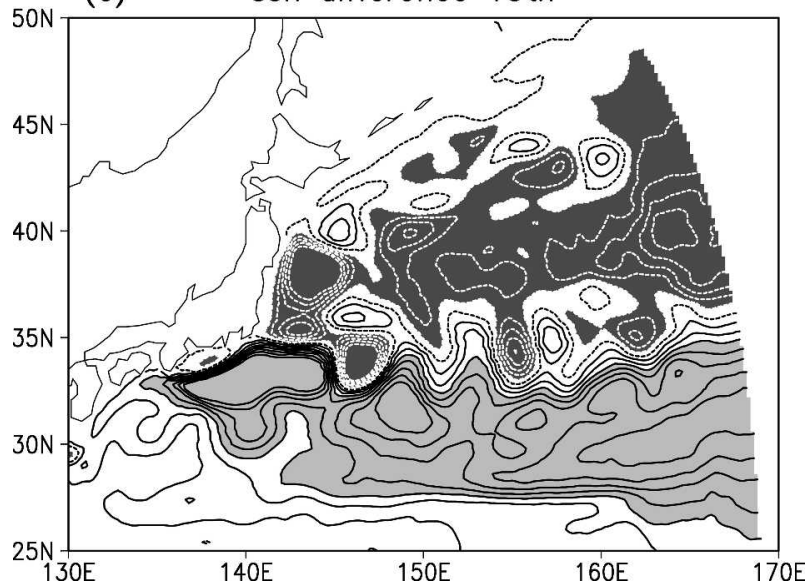

FIG. 4. Ensemble and annual mean of SSH difference fields (forced minus control case) for (a) first, (b) second, and (c) third year after the anomalous forcing is imposed. Contour interval is $0.02 \mathrm{~m}$ with light shading: $>0.04 \mathrm{~m}$ and dark shading: $<-0.04 \mathrm{~m}$. becomes unclear farther to the west. This suggests that mesoscale eddies might mask out the forced signal and/ or some nonlinear mechanism becomes important in the western basin. In fact, the recirculation, a feature due to nonlinear dynamics, cuts across the $29^{\circ} \mathrm{N}$ latitude around $145^{\circ} \mathrm{E}$ (Fig. 2). The weak decay of SSH anomalies toward the west may be due to horizontal/ vertical mixing in the model.

We note that significant SSH anomalies appear near the Japanese coast at year 1, long before the arrival of the baroclinic waves induced by the eastern boundary forcing (Fig. 4a). The exact cause of these anomalies in the far west is unclear but may be due to a number of factors. First, the ocean internal variability is strong near the coast, which may contaminate the forced response. Another possibility is the interaction between baroclinic and barotopic modes. Although no anomalous volume transport is imposed at the eastern boundary, barotropic Rossby waves, which propagate much faster, could be induced by anomalous baroclinic forcing.

\section{Steady response}

\section{a. KE front}

Figure 6a displays ensemble and temporal mean SSH difference similar to Fig. 4, but averaged over the 6th to 10th year after the anomalous forcing is imposed, a period during which the model has reached a steady state as discussed in the previous section. The most distinct feature in this difference field is the strengthening of the KE front: SSH difference contours are concentrated in a narrow latitudinal band between $33^{\circ}$ and $34^{\circ} \mathrm{N}$, as opposed to a smoother field near the eastern boundary where the lateral forcing is applied. The $\mathrm{KE}$ front intensification is better illustrated by the zonal current velocity difference at $50-\mathrm{m}$ depth (Fig. $6 \mathrm{~b}$ ), with a strong eastward acceleration along $33^{\circ}-$ $34^{\circ} \mathrm{N}$. The difference field is constructed using a total of $50 \mathrm{yr}$ of model simulation from both the control and forced ensembles. Considering that the time scale of ocean mesoscale eddies is mostly shorter than 180 days (e.g., Ebuchi and Hanawa 2000), we estimate that there are $\left(N_{\text {control }}+N_{\text {forced }}-2\right)$ degrees of freedom, where $N_{\text {control }}=N_{\text {forced }}=100$. A student's $t$ test puts most of the SSH difference field above the 95\% significance level (shown with light shading in Fig. 6a).

Figures $6 c-d$ compare zonal averages between the model interior $\left(142.5^{\circ}-163^{\circ} \mathrm{E}\right.$ : solid lines) and eastern boundary (dashed lines). The zonal averaging is done over five quasi-stationary waves along the $\mathrm{KE}$ in the SSH difference (section $4 \mathrm{~b}$ ) and is nearly free of their influence on the statistics. While the imposed forcing is quite smooth near the eastern boundary, the ocean dy- 

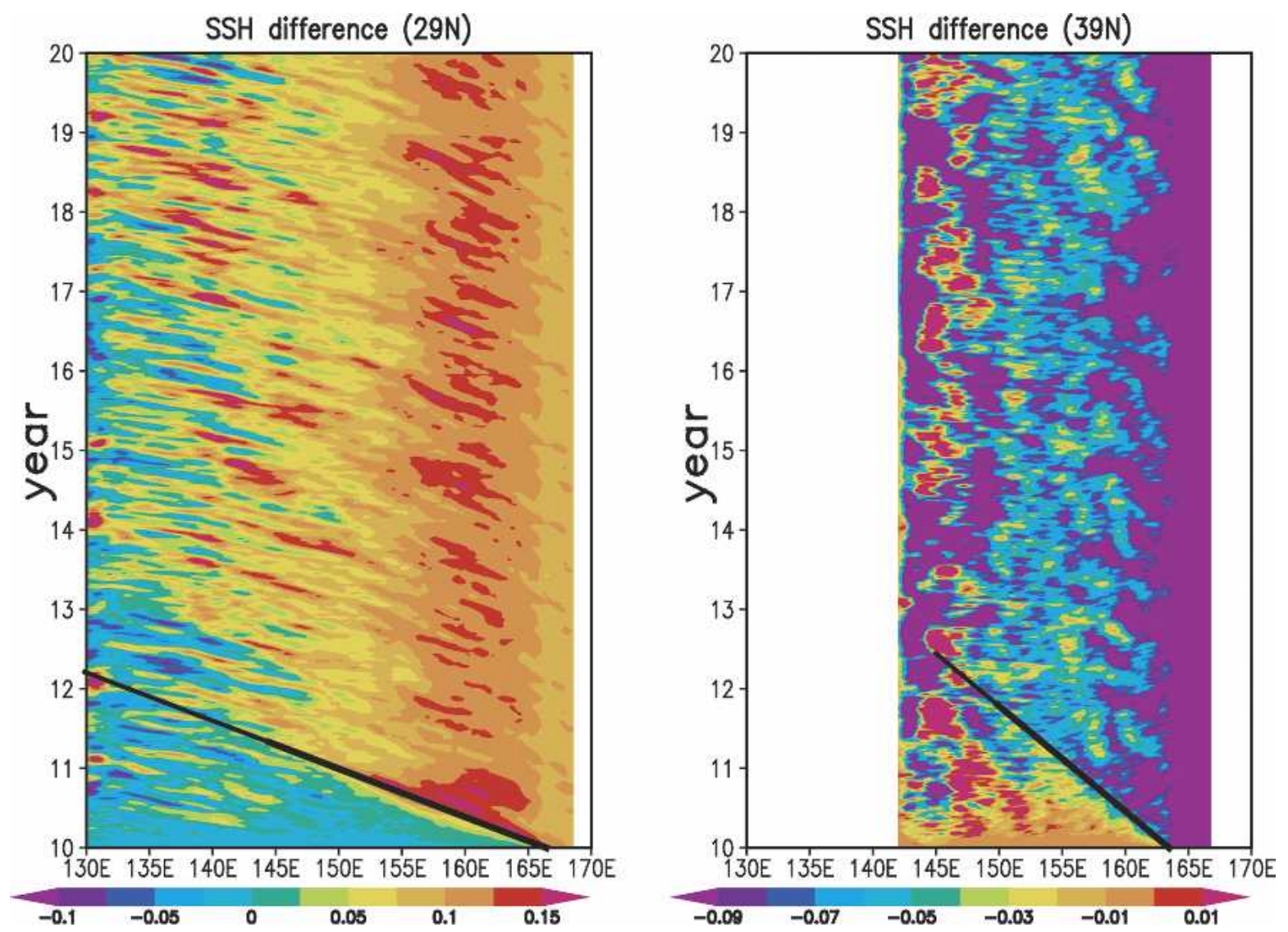

FIG. 5. Longitude-time section of ensemble mean of SSH difference fields in meter (forced minus control case) at (left) $29^{\circ}$ and (right) $39^{\circ} \mathrm{N}$. Scale of shading is shown in the bottom of each panel. A constant phase line of the westward-propagating SSH difference is also shown in each panel.

namics organizes the SSH response to form sharp gradients at $32^{\circ}-34^{\circ} \mathrm{N}$. The contrast between the interior response and the lateral forcing is more striking in the zonal velocity at $50 \mathrm{~m}$ (Fig. 6d). In response to a broad eastward acceleration imposed near the eastern boundary, anomalous currents are organized into several jets with alternating directions. While the imposed eastward acceleration is $9^{\circ}$ wide in latitude, the major anomalous eastward jet is much more intense and considerably narrower, only $3.5^{\circ}$ in width. Centered near the KE front $\left(33^{\circ}-34^{\circ} \mathrm{N}\right)$, this major jet exists continuously from the Japanese coast to the eastern boundary and is the focus of this study. While not discussed further here, we note a minor eastward jet in Figs. $6 \mathrm{~b}$ and $6 \mathrm{~d}$ farther to the north at $37.5^{\circ} \mathrm{N}$, which might be related to the Oyashio front that is not fully developed in the control run (Fig. 2). For reasons not clear at this time, a high-resolution $\left(0.1^{\circ}\right)$ global OGCM on Japan's Earth Simulator captures this Oyashio front's interannual variability quite well (M. Nonaka 2004, personal communication).

In addition to the narrow acceleration of the KE cur- rent, the latitude of the maximum zonal current shifts slightly southward in response to the imposed lateral forcing (Fig. 6e). This KE southward shift appears to be consistent with Deser et al.'s (1999) observations that the geostrophic transport is intensified along KE's southern flank from the 1970s to 1980s (their Fig. 10). Recently, Joyce and Dunworth-Baker (2003) analyzed hydrographic data for two periods, 1945-75 and 197698, that span the regime shift. They found negative dynamic height anomalies, as well as negative anomalies of temperature and salinity along the $\mathrm{KE}$ axis in the second period, indicative of a southward shift of the KE.

\section{b. Stationary meanders}

Stationary eddies are superimposed on the KE acceleration in the SSH difference map (Fig. 6a), all of them significant at the $95 \%$ level. Figure 7 compares the $\mathrm{SSH}=0.7 \mathrm{~m}$ contour line, a geostrophic streamline taken to represent the KE axis, between the control and forced ensembles. The first trough of the KE's stationary meanders east of Japan deepens while the subse- 
(a)

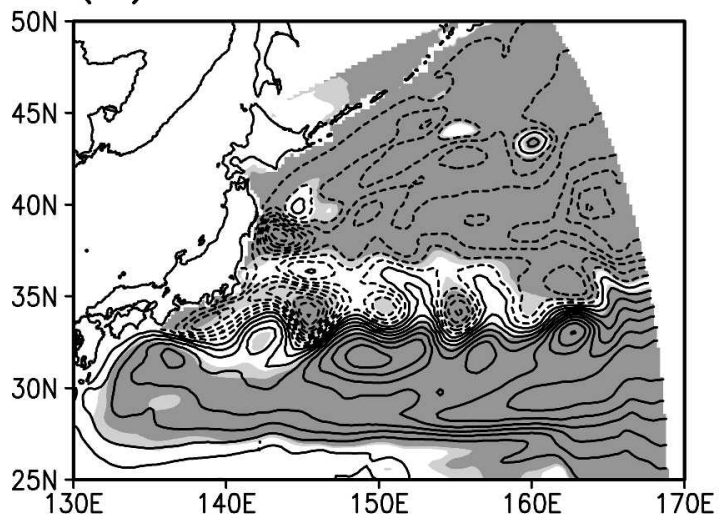

(b)

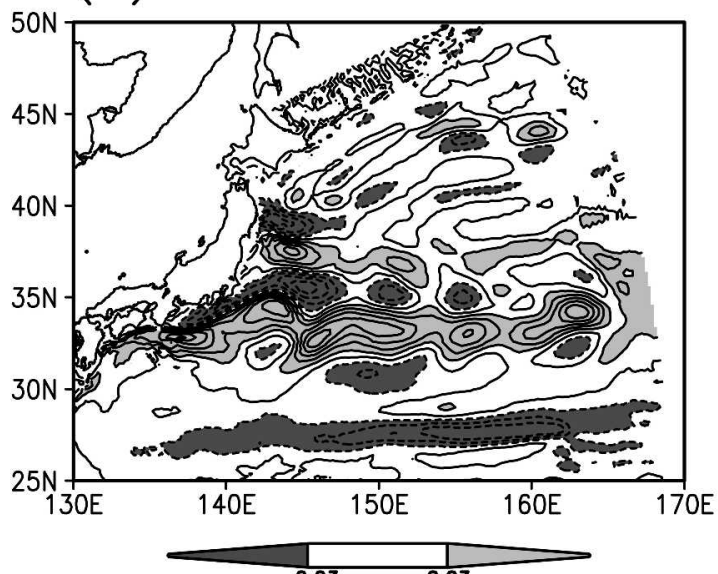

$: 167 \mathrm{E}$

(c) $: 167 \mathrm{E}$

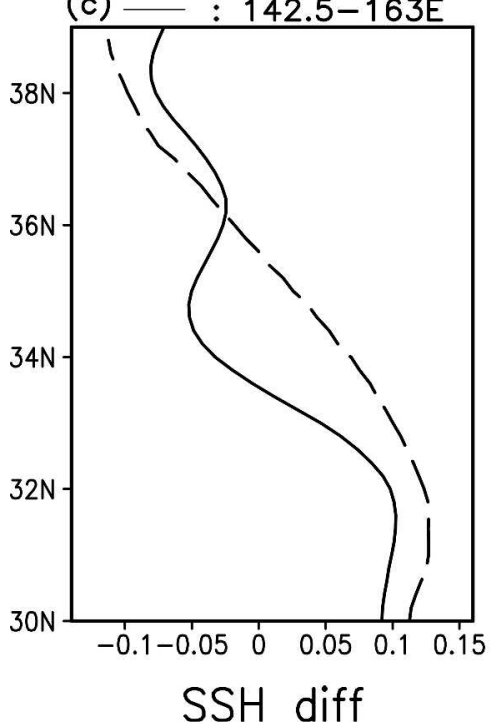

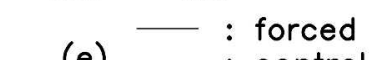

(e) - : forced

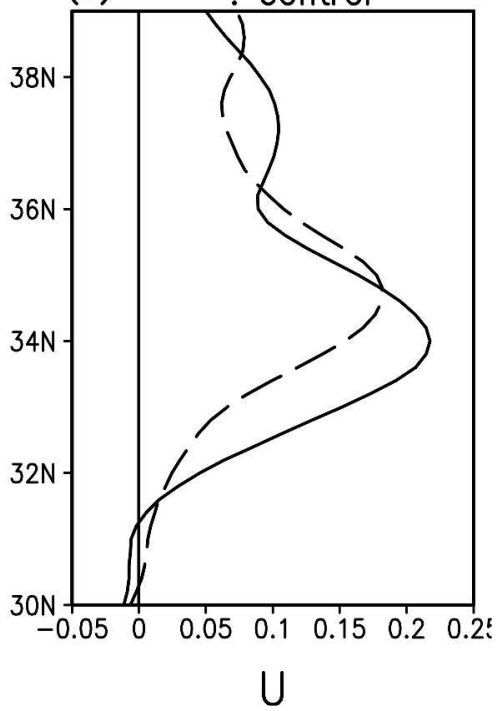

FIG. 6. (a) Ensemble and temporal mean (over 16th-20th years) of SSH difference fields (forced minus control case). Contour interval is $0.02 \mathrm{~m}$ with light shading: > the statistical confidence level of $95 \%$ and dark shading: > that of $99 \%$. (b) As in (a) but for the $50-\mathrm{m}$ zonal velocity. Contour interval is $0.03 \mathrm{~m} \mathrm{~s}^{-1}$. Meridional profiles of (c) zonally averaged ensemble and temporal mean SSH difference, (d) 50-m-depth zonal velocity difference, and (e) 50-m-depth zonal velocity. Temporal means are taken over the 16th-20th years. In (c) and (d) solid lines show the zonally averaged profiles over the interior domain of the regional OGCM $\left(142.5^{\circ}-163^{\circ} \mathrm{E}\right)$ whereas dashed lines show profiles at $167^{\circ} \mathrm{E}$ near the eastern boundary of the regional OGCM. In (e) the solid line shows the forced case and the dashed line shows the control case.

quent ridges and troughs shift consistently eastward, leaving significant negative $\mathrm{SSH}$ anomalies at $150^{\circ}$, $155^{\circ}$, and $160^{\circ} \mathrm{E}$. A close look indicates an increase in stationary wavelength east of the first trough in the forced ensemble. This is consistent with the stationary Rossby wave theory in an eastward flow (e.g., Mizuno and White 1983), which predicts the wavelength $L$ as

$$
L=2 \pi \sqrt{U / \beta}
$$

where $U$ is the background zonal velocity and $\beta$ is the meridional gradient of the Coriolis parameter. Taking the zonal background velocities as $18 \mathrm{~cm} \mathrm{~s}^{-1}$ for the control and $21 \mathrm{~cm} \mathrm{~s}^{-1}$ for the forced run (Fig. 6e) and $\beta=1.89 \times 10^{-11} \mathrm{~m}^{-1} \mathrm{~s}^{-1}$, Eq. (1) gives about a $0.5^{\circ}$ increase in the wavelength, roughly in agreement with the model result.

\section{c. Transient eddies}

Here we examine transient eddies and their response to incoming Rossby waves. Transient eddies are defined as the deviation from ensemble and monthly 


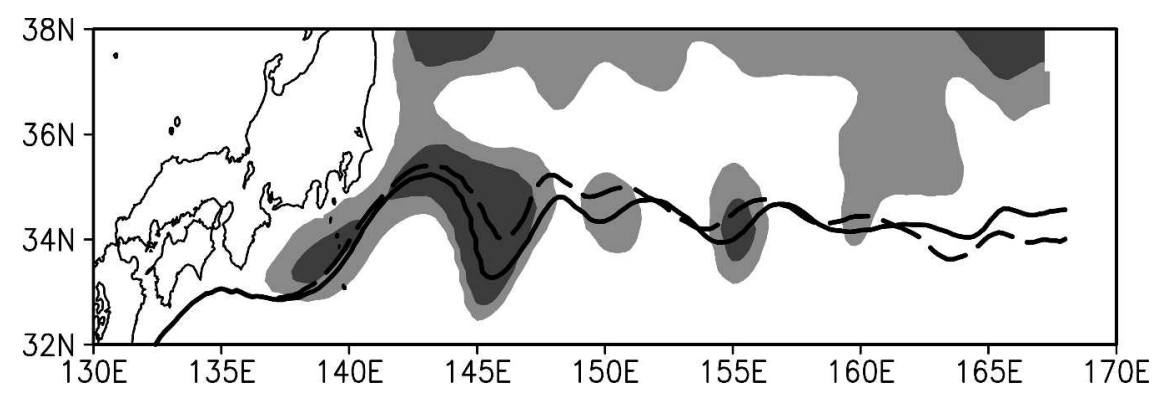

FIG. 7. Ensemble and temporal mean (over the 16th-20th years) of SSH difference fields (light shading: $<-0.04 \mathrm{~m}$ and dark shading: $<-0.08 \mathrm{~m}$ ). Also drawn are the $0.7-\mathrm{m}$ contour lines of ensemble and temporal mean SSH for the forced case (solid) and the control case (dashed).

mean values. The anomalies are further decomposed into low- and high-frequency components by using a recursive-type high-pass filter with the half-power cutoff period at 300 days.

Figure 8 shows the root-mean-square (rms) variance of SSH in the low- (upper panels) and high- (lower panels) frequency bands. Low-frequency variance features two major maxima south of Japan at $135^{\circ}-140^{\circ} \mathrm{E}$ and to the southeast over the first stationary meander of the KE, respectively. These maxima are associated with the changes in the Kuroshio's path south of the Japan. Variability in these two centers of action is cor-
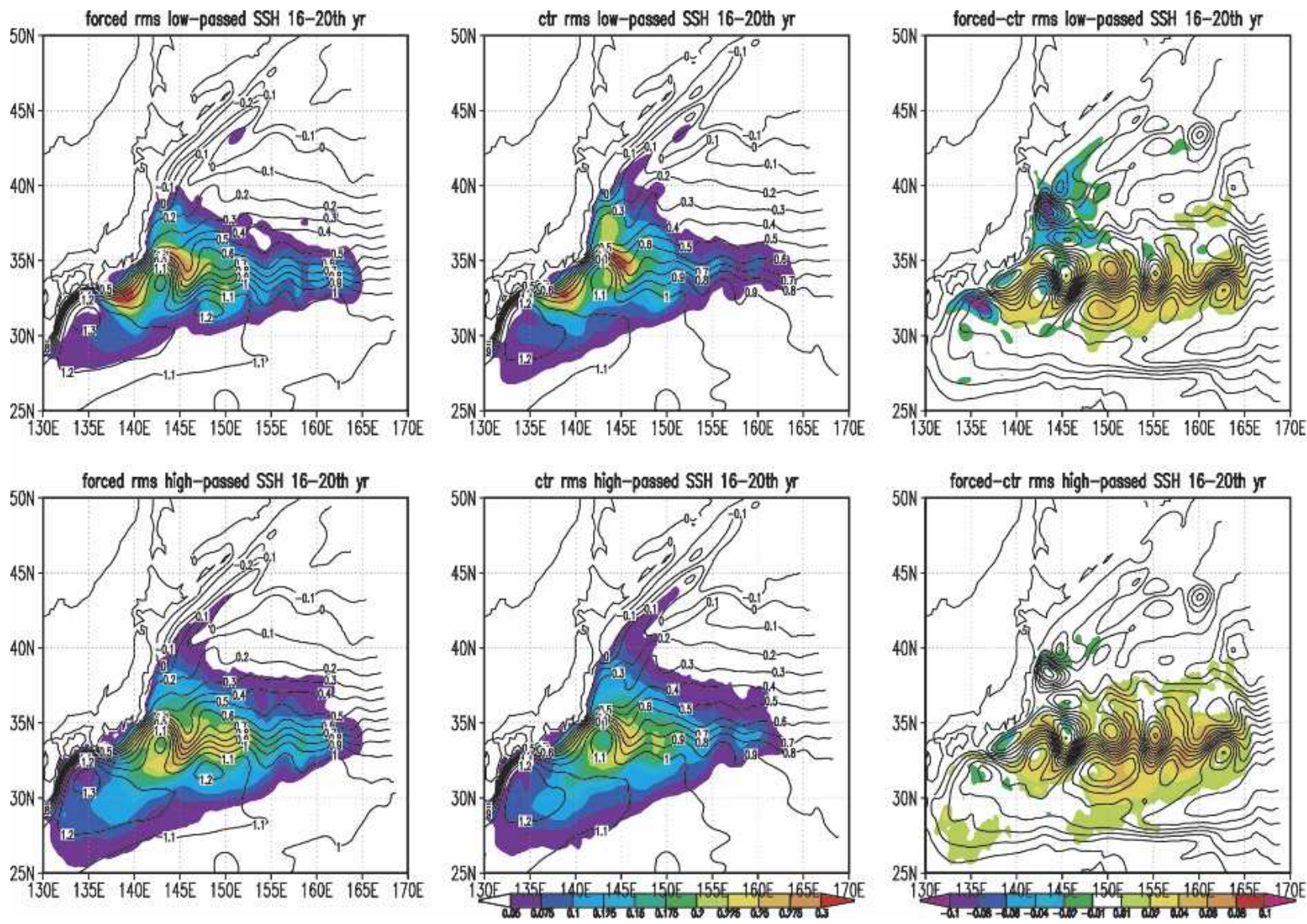

FIG. 8. Rms SSH [(left) the forced ensemble and (middle) the control ensemble] and (right) difference between the forced and the control case. (top) Low-frequency component (longer than a year) and (bottom) high-frequency component (less than a year). Color bar is shown below the lower-middle panel for the rms SSH and below the lower-right panel for the rms SSH difference. (left), (middle) Mean SSH and (right) its difference contours are superimposed. 

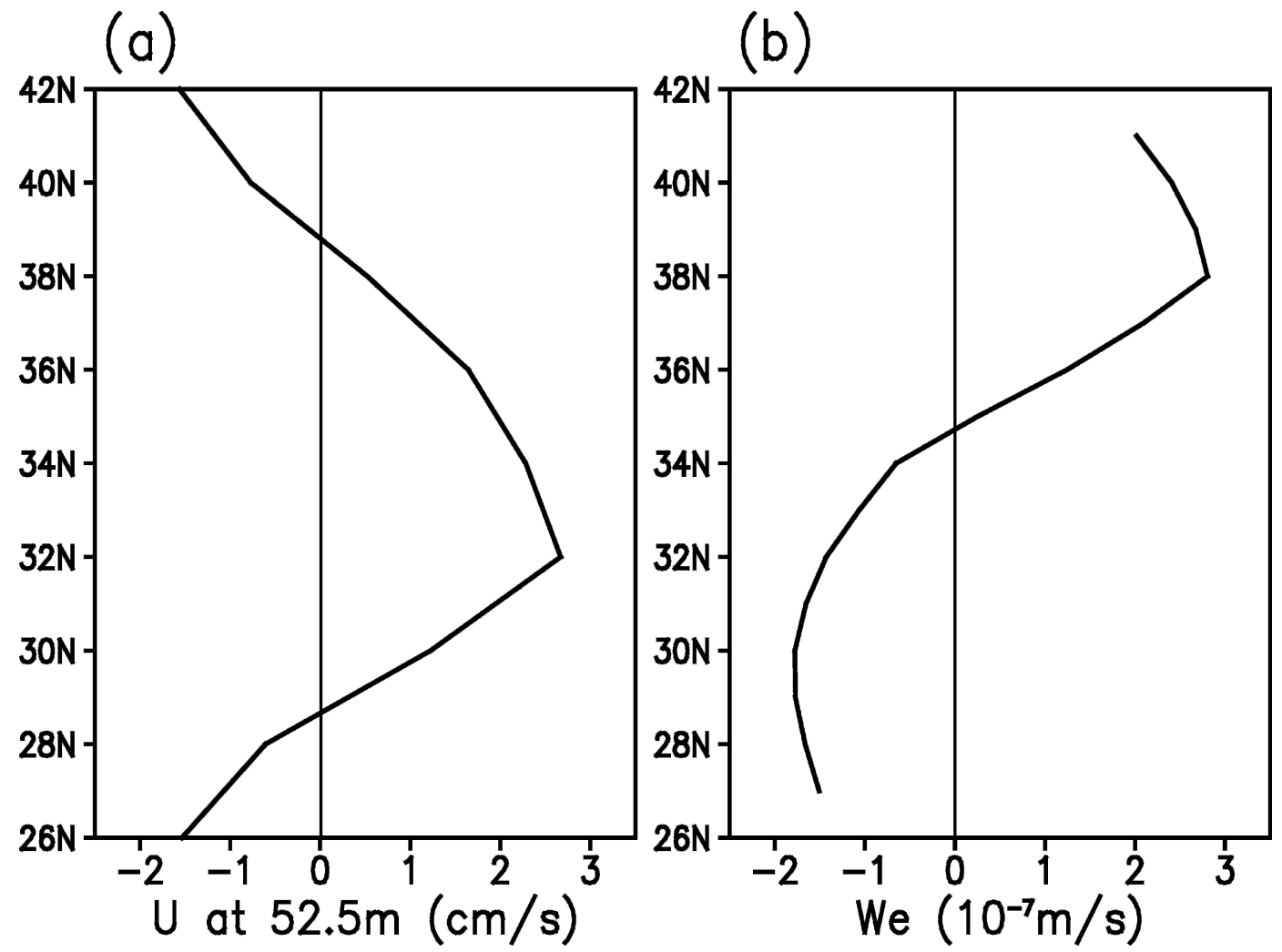

FIG. 9. Decadal change in zonal current at $52.5 \mathrm{~m}$ averaged over the western North Pacific $\left(141^{\circ}-161^{\circ} \mathrm{E}\right)$ between the period 1972-78 and the period 1979-90, calculated from the coarse-resolution OGCM simulation (Xie et al. 2000). Unit in $\mathrm{cm} \mathrm{s}^{-1}$. (b) Decadal change in Ekman pumping velocity averaged over the central to eastern Pacific $\left(160^{\circ} \mathrm{E}-140^{\circ} \mathrm{W}\right)$ between the period $1966-75$ and the period $1976-85$ based on NCEP-NCAR reanalysis. Unit in $10^{-7} \mathrm{~m} \mathrm{~s}^{-1}$.

related with each other: when the Kuroshio south of Japan takes a southern path (large meander: Kawabe 1995), it tends to overshoot and separate from the Japanese coast farther to the north (not shown). In addition to these major maxima near Japan, low-frequency variance is high along the KE. Similarly, the high-frequency variance reaches a meridional maximum along the $\mathrm{KE}$ front. In addition, there is a "storm track" along the southeast flank of the recirculation where the highfrequency variance is high. Anticyclonic eddies that travel southwestward in this slanted storm track sometimes trigger large meanders of the Kuroshio (Mitsudera et al. 2001; Waseda et al. 2002, 2003).

In the forced ensemble, transient eddy activity is visibly elevated along the KE front in both frequency bands compared to the control (Fig. 8, right panels), a change consistent with increased baroclinicity due to the $\mathrm{KE}$ acceleration. There is no significant change in the high-frequency storm track on the southeast flank of the recirculation, by contrast, perhaps because of little changes in this part of the recirculation.

\section{Discussion}

This section discusses possible mechanisms for the narrow acceleration of the KE current in the forced ensemble. First let us consider the linear Rossby wave adjustment, which leaves the ocean in Sverdrup balance upon its passage:

$$
U_{g}=-\frac{f}{\beta} \int_{x_{E}}^{x} \frac{\partial w_{e}}{\partial y} d x
$$

where $U_{g}$ is the vertical-integrated zonal transport, $f$ is the Coriolis parameter, $w_{e}$ is the Exman pumping velocity, $x$ is the zonal coordinate, and $x_{E}$ its value at the eastern boundary of the ocean basin. According to Eq. (2), the meridional scale of $U_{g}$ is the same as that of the wind forcing $w_{e}$, which is generally of the large scale associated with the atmospheric Aleutian low. In Xie et al.'s (2000) coarse-resolution OGCM, this linear Sverdrup relation is indeed dominant (Fig. 9). While having not configured a low-resolution of the regional OGCM, we suspect that its behavior is close to that of Xie et al.'s 


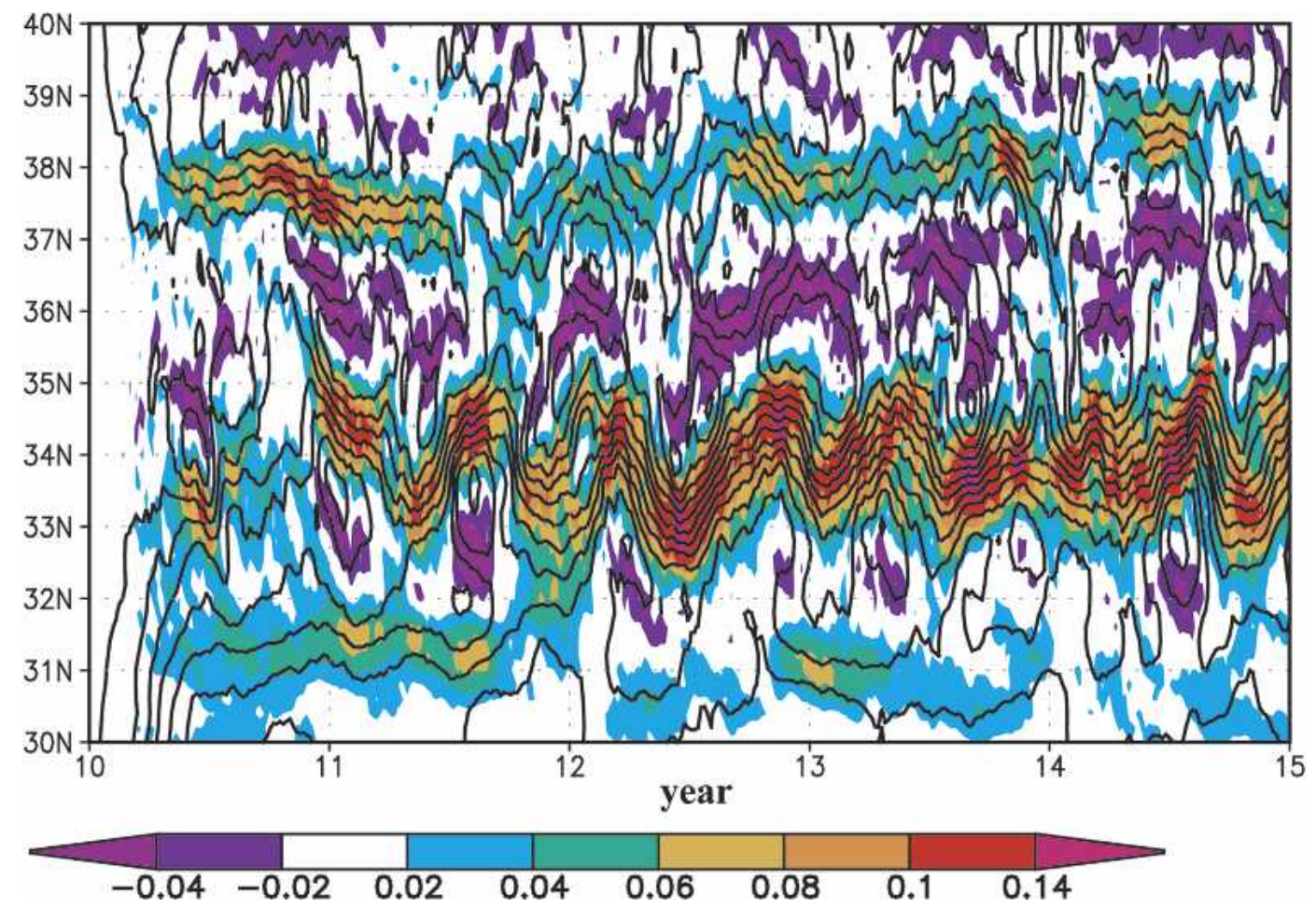

FIG. 10. Time-latitude section of the difference in the ensemble means of zonal mean $u$ velocity at 50-m depth (color shade with color bar at bottom; unit in $\mathrm{m} \mathrm{s}^{-1}$ ) and SSH (contours with $0.02-\mathrm{m}$ interval). The zonal average is taken over $159^{\circ}-163^{\circ} \mathrm{E}$. Tick marks on the abscissa indicate the end of model years. The axis covers first $5 \mathrm{yr}$ after the anomalous forcing is imposed.

OGCM and follows the Sverdrup dynamics. The broad eastward acceleration takes place in the latitudinal band of $28^{\circ}-38^{\circ} \mathrm{N}$ between the $w_{e}$ extrema. In our regional model domain without local wind anomalies, Eq. (2) requires $U_{g}=U_{0}$, where $U_{0}$ is the zonal velocity imposed on the eastern buffer zone of the model. Therefore, the linear Sverdrup theory does not explain the narrow acceleration of the KE simulated in our high-resolution regional model. ${ }^{1}$ Some mechanisms other than the linear theory are thus necessary.

To see how the narrow acceleration of the KE front current is established in time, we show in Fig. 10 a latitude-time section of the differences in SSH (contour) and zonal velocity at $50 \mathrm{~m}$ between the forced and control ensembles, zonally averaged over one stationary wavelength near the model eastern boundary. The $\mathrm{KE}$ acceleration (in $33^{\circ}-35^{\circ} \mathrm{N}$ ) takes place in two stages. The first stage occurs in the first year, with SSH anomaly contours nearly equally spaced at $30^{\circ}-35^{\circ} \mathrm{N}$ in

\footnotetext{
${ }^{1}$ This is true only for steady-state response. The same linear dynamics allow narrow zonal acceleration in response to broadscale wind forcing that varies in time (e.g., Qiu 2003), because of varying phase speed of Rossby waves in the meridional direction.
}

association with a broad and moderate acceleration in the eastward current. It appears to be associated with the passage of the barolinic Rossby waves with possibly some feedback from eddies. The second stage takes place in the second year, and the KE jet is further accelerated with several SSH anomaly contour lines moving from $31^{\circ}-32^{\circ} \mathrm{N}$ northward to form a sharp front around $34^{\circ} \mathrm{N}$. This delayed KE acceleration might be due to the anomalous gyre that is spun up after the boundary-forced Rossby waves have arrived at the western boundary, a mechanism the rest of this section explores.

\section{a. Spinup of the inertial boundary current in a quasigeostrophic model}

First, we use a three-layer quasigeostrophic (QG) model (see appendix for its description) to demonstrate the concept of the inertial boundary current adjustment in response to wind changes. The experimental design for the QG model is the same as that for the regional OGCM. First we force the QG model with an Ekman pumping forcing

$$
w_{e}=W_{0} \sin \frac{\pi y}{L} \text { for }-L \leq y \leq L,
$$



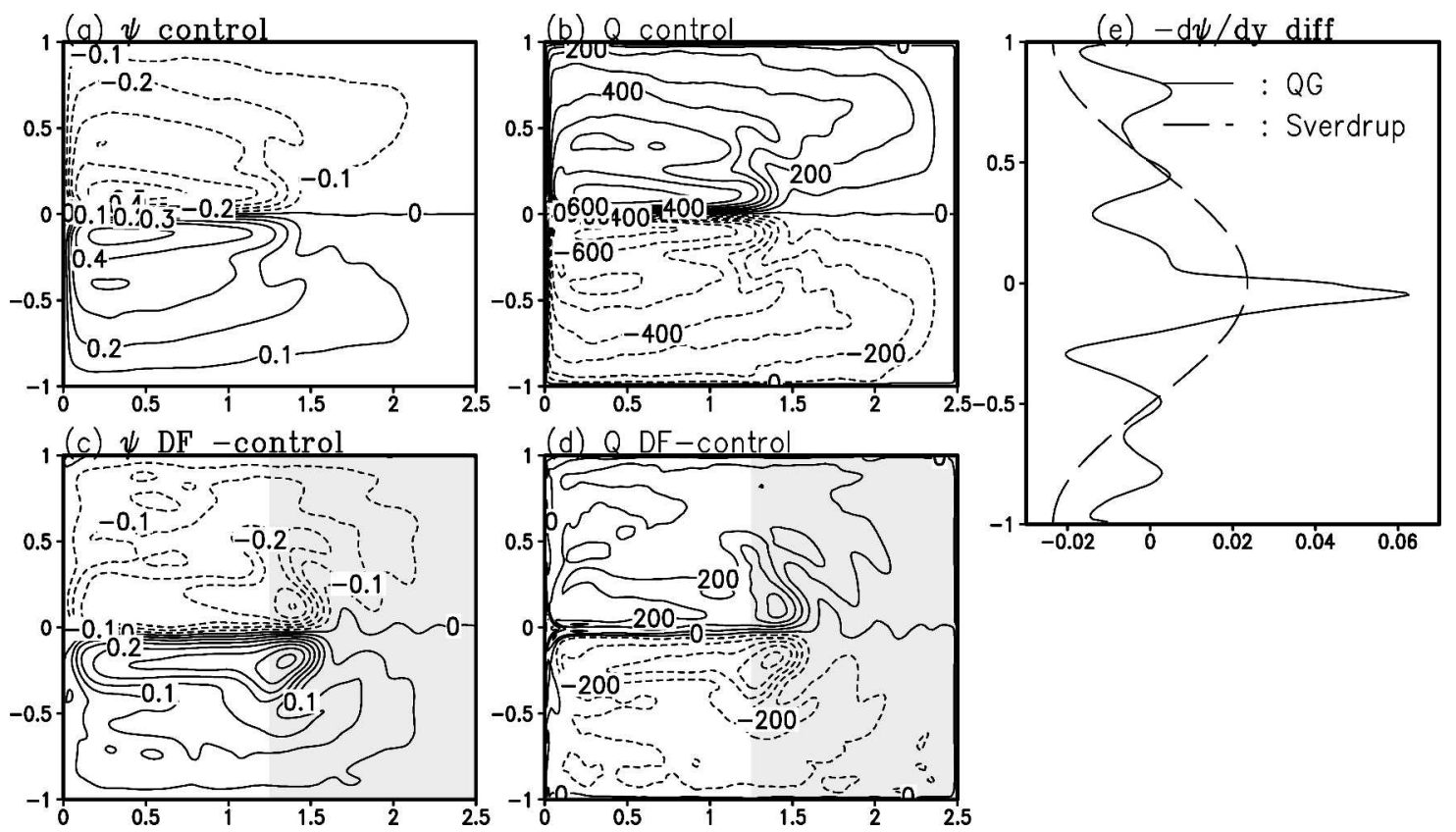

FIG. 11. (a) Mean first-layer streamfunction in the control run from the QG model. Temporal mean is taken over $2 \tau<\mathrm{t}<3 \tau$. (b) Mean first-layer PV in the control run. (c), (d) As in (a), (b) but for the difference between the DF run and the control run. The regions where the amplitude of the forcing is doubled are lightly shaded in (c)-(d). (e) The mean first-layer zonal current difference (solid line) zonally averaged over the western half of the domain. Anomalous Sverdrup zonal-mean zonal current profile calculated by anomalous Ekman pumping forcing is shown in dashed line.

where $2 L$ is the meridional width of the model domain. This wind forcing gives rise to a symmetric double-gyre circulation with the intergyre boundary at $y=0$ (Fig. 11a). In the control run the magnitude of Ekman pumping velocity is chosen to be $W_{0}=3 \times 10^{-6} \mathrm{~m} \mathrm{~s}^{-1}$ over the whole basin. In the second run (DF run hereafter), the wind forcing is doubled in the eastern half of the basin while remaining the same in the western half. While the QG approximation and the symmetric double-gyre forcing are an oversimplification of the North Pacific circulation, the model seems adequate for a qualitative demonstration of how a broad-scale forcing can lead to narrow jets.

We use the time means for $2 \tau \leq \mathrm{t} \leq 3 \tau$ to represent the steady state, where $\tau=2.38 \mathrm{yr}$ is the time for the baroclinic Rossby wave to cross the basin (appendix). The first-layer streamfunction for the control run (Fig. 11a) shows a familiar double-gyre circulation, with a pair of recirculations on both sides of the gyre boundary in the western basin. Between the recirculations is a narrow intense eastward jet as an extension of the western boundary currents, analogous to the KE. Figure 11b shows the potential vorticity (PV) in layer 1 , featuring a pair of $\mathrm{PV}$ maximum and minimum to the north and south of the western boundary current (WBC) extension, respectively, reminiscent of inertial circulation derived by Fofonoff (1954). In a purely inertial limit, the
PV is conserved along the streamline, and the advection of low (high) PV water from the subtropics (subarctic) causes a deficit (excess) in PV south (north) of the WBC extension, which induces negative (positive) relative vorticity and the anticyclonic (cyclonic) recirculation (Cessi et al. 1987).

In response to the doubling of the wind forcing in the eastern basin, besides a broad-scale adjustment in the Sverdrup gyres, the recirculations intensify in the western basin at a shorter meridional scale (Fig. 11c). As a result, the WBC extension accelerates, forming a narrow anomalous jet in contrast to a much broader eastward acceleration inferred from the Sverdrup dynamics (Fig. 11e). This nonlinear response of the WBC extension is analogous to our regional OGCM response to broad-scale lateral forcing on the eastern boundary.

Figure 11d shows the PV difference between the forced and control runs of the QG model. The PV front on the boundary of the subarctic and subtropical recirculations intensifies, with positive and negative PV anomalies north and south to the WBC extension, respectively. These PV anomalies, in turn, are a result of intensified PV advection from the western boundary layer. Thus, the Rossby waves excited in the eastern basin trigger nonlinear interaction of the WBC extension, its PV advection, and inertial recirculations. The resultant spinup of the recirculations features narrow 
anomalous zonal jets with a meridional structure that differs strikingly from the imposed broader-scale wind forcing.

\section{b. PV adjustment}

Now we examine the PV adjustment in the regional OGCM and see if similar PV anomalies appear. In the $z$ coordinate, $\mathrm{PV}$ is defined as

$$
Q=\frac{f+\zeta}{\rho} \frac{\partial \rho}{\partial z},
$$

where $\zeta$ is the relative vorticity and $\rho$ is the density. In the isopycnal coordinate, the Bernoulli function $\Gamma\left(\sigma_{\theta}\right)$ represents the geostrophic streamfunction. Here we use an approximate form (e.g., Rothstein et al. 1998),

$$
\Gamma\left(\sigma_{\theta}\right)=\rho_{0} g \eta+g \int_{z\left(\sigma_{\theta}\right)}^{0}\left[\rho-\rho\left(\sigma_{\theta}\right)\right] d z,
$$

where $\eta$ is SSH.

Figure 12 shows the ensemble and temporal mean of the Ertel PV and Bernoulli function on the $26.4 \sigma_{\theta}$ surface. In both the control and forced ensembles, there is a sharp PV front along the KE, much as in the QG model. There is a distinct band of PV maximum north of the front with PV decreasing rapidly to the south. There is a well-defined anticyclonic recirculation south of the KE front, apparently consistent with the PV distribution. The PV front strengthens in the forced ensemble, as illustrated by the PV difference from the control. While the anomaly pattern is somewhat complicated, PV generally decreases south of the front, consistent with the enhanced advection of low PV water of subtropical origin by the intensified KE.

Because of large variability around the KE front, the Eulerian mean may have resulted in a too-diffused PV front. This motivates us to average PV on a stream coordinate by following the KE axis, which is defined as the maximum zonal current velocity for each longitude at each time step. Averaged in this stream coordinate, the PV front indeed becomes much sharper than that in Eulerian coordinates, with a well-defined maximum to the north (Figs. 12d,e). South of the front, a PV minimum is visible at some longitudes (e.g., $140^{\circ}-150^{\circ} \mathrm{E}$ ), presumably due to the advection by the Kuroshio and its extension. Furthermore, strengthening of the PV front and PV reduction south of the KE become more visible than in the Eulerian framework. The PV adjustment and its similarity to the QG model response leads us to suggest that the narrow eastward acceleration of the KE current in our regional OGCM is part of the response of the inertial recirculation to incoming Rossby waves.

This hypothesis remains to be tested with more detailed PV diagnostics. While the PV dynamics for the ocean have been studied in QG models (e.g., Holland et al. 1984) and there are several attempts at PV analysis in multilevel OGCMs (Nakamura and Chao 2001; Gille 1997), a PV diagnostic framework that is easy to use and with better interpretive power, such as the Eliassen-Palm flux and its variants for atmospheric diagnosis, needs to be developed for better understanding interaction of inertial currents and eddy feedback in ocean level models as well as in observations.

\section{c. Eddy feedback to the mean flow}

We now turn our attention to transient eddy feedback to the mean flow. Figure 13a shows the Reynolds stress, $\left\langle u^{\prime} v^{\prime}\right\rangle$, at 50-m depth for the control run. Here the prime denotes eddy components defined as deviation from the ensemble and monthly mean, and the bracket designates ensemble and temporal mean for the last $5 \mathrm{yr}$ of the integrations. Along the path of the Kuroshio south of Japan and its extension, positive and negative centers appear alternately: negative around $137^{\circ} \mathrm{E}$, positive downstream hugging the south coast of Japan, negative at the first crest of the KE stationary meanders, and positive around $147^{\circ} \mathrm{E}$ east of the first trough. Except for the first negative center that might be associated with Kuroshio transient meanders, the $\left\langle u^{\prime} v^{\prime}\right\rangle$ pattern in the control run is very similar to that estimated from the altimetry observations (Plate 8b of Ducet and Le Traon 2001 and Fig. 9b of Niiler et al. 2003), which coincide with a period when the Kuroshio south of Japan experiences very few large meander events.

Farther downstream, $\left\langle u^{\prime} v^{\prime}\right\rangle$ tends to be positive and negative south and north of the KE current, respectively. Figure 13b shows the zonal-mean Reynolds stress convergence in the control run. The maximum eddy acceleration corresponds well to the KE (Fig. 6e), indicative of a positive feedback onto the mean current. This tendency is in agreement with previous studies based on sparse observations (e.g., Tai and White 1990). The meridional momentum transport $\left\langle u^{\prime} v^{\prime}\right\rangle$ is not the only major term, but the zonal transport $\left\langle u^{\prime 2}\right\rangle$ is equally important for the tendency of the zonal current as pointed out by Ducet and Le Traon (2001).

Figure $13 \mathrm{c}$ displays zonal-mean Reynolds stress convergence difference between the forced and control ensembles. Again, it shows good correspondence to the anomalous currents in the time mean (gray line redrawn from Fig. 6d), with positive peaks at $33^{\circ}-34^{\circ} \mathrm{N}$ and $37^{\circ}-38^{\circ} \mathrm{N}$ and negative peaks at $35^{\circ}-36^{\circ}$ and $39^{\circ} \mathrm{N}$. 

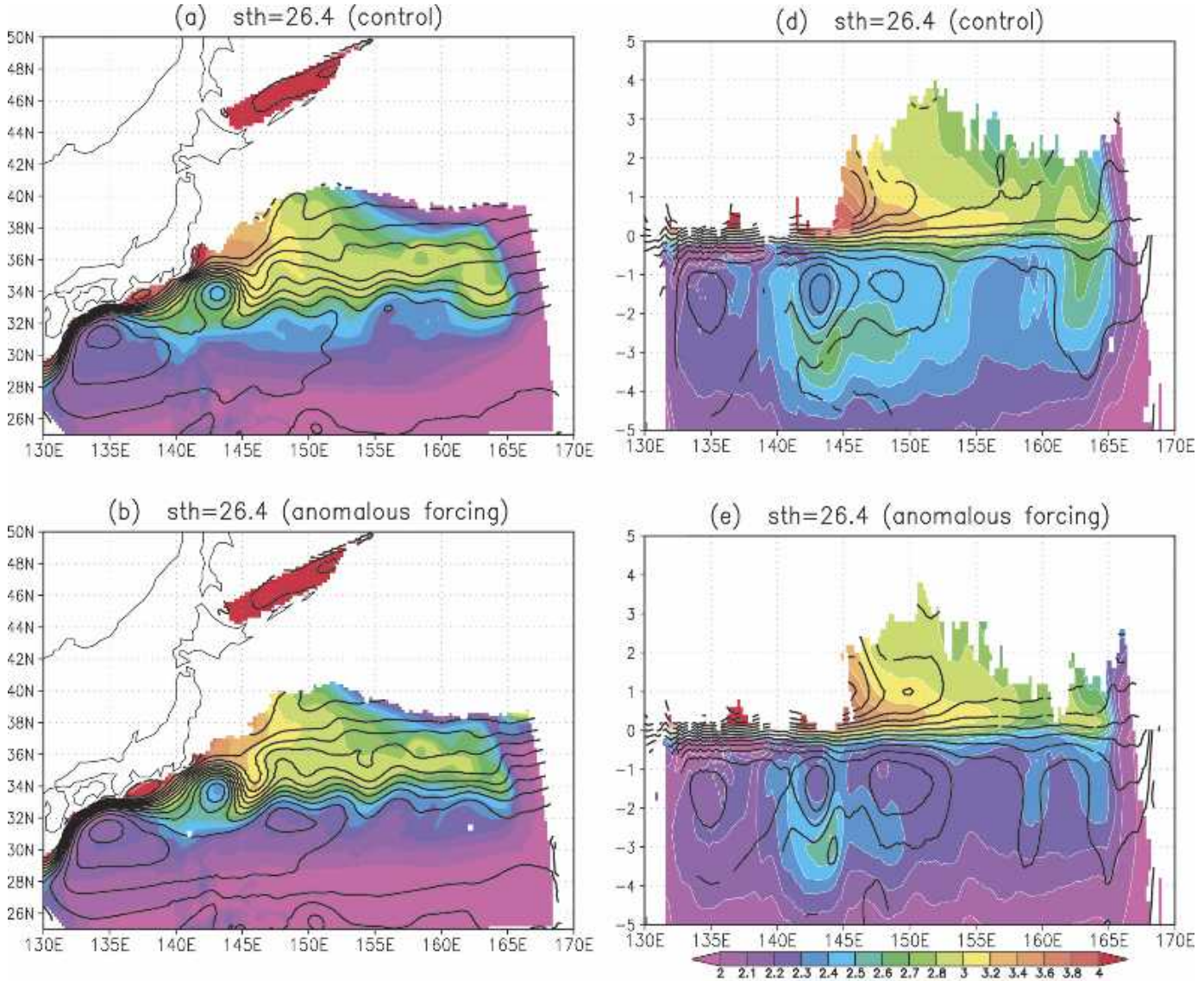

(c) $s$ th $=26.4$ (anomalous forcing-control)
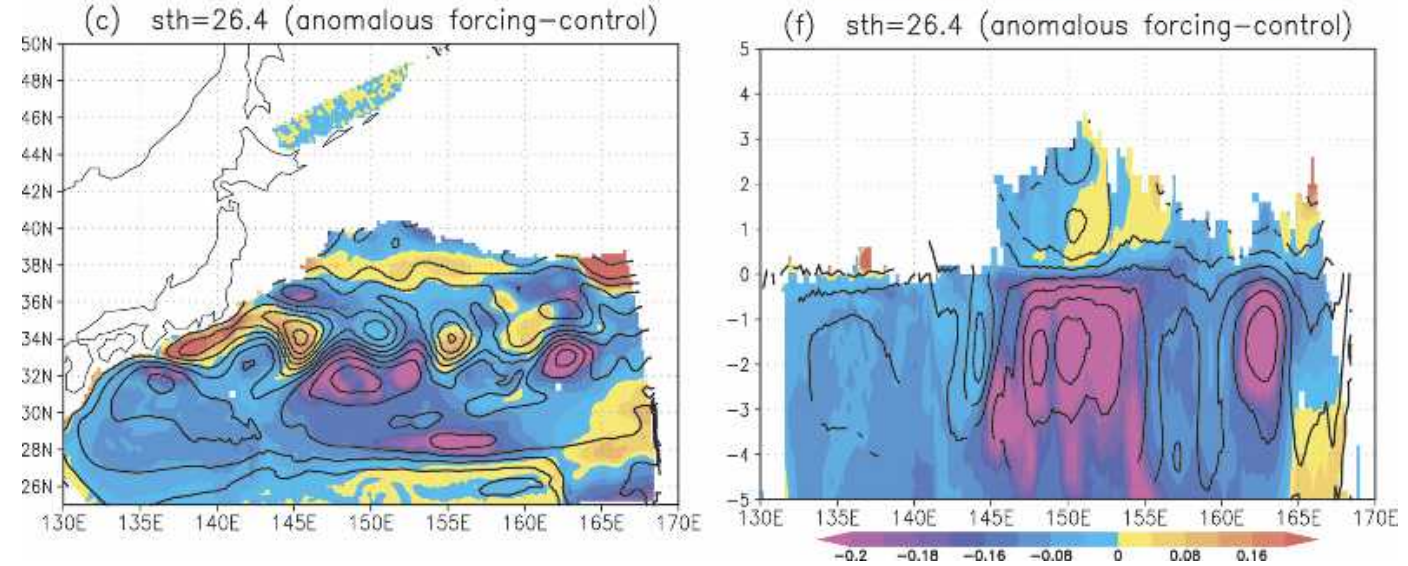

FIG. 12. Ensemble and temporal mean (16th-20th years) of PV on the isopycnal of $26.4 \sigma_{\theta}$ averaged on (a)-(c) the fixed coordinate and (d)-(f) the stream coordinate (unit of the $y$ axis is degree from the KE jet): (a), (d) the control run, (b), (e), the forced run, and (c), (f) their differences. Color bar at the bottom of (e) applies for (a), (b), (d), and (e), and color bar at the bottom of (f) applies for (c) and (f).

Thus, transient eddy transport momentum acts to strengthen the time-mean currents, but the importance of this eddy feedback needs to be evaluated in future studies relative to other terms in the momentum equation. Again this calls for developing a systematic and insightful diagnostic framework for eddy-mean flow in- teraction in continuously stratified oceans, a task that is beyond the scope of this study.

Regarding the eddy-mean flow interaction and the narrow acceleration of the KE current, it is interesting to note that similar scale reductions take place in the atmosphere as well, in response to global-scale forcings. 
(a) control $\left\langle u^{\prime} v^{\prime}\right\rangle$

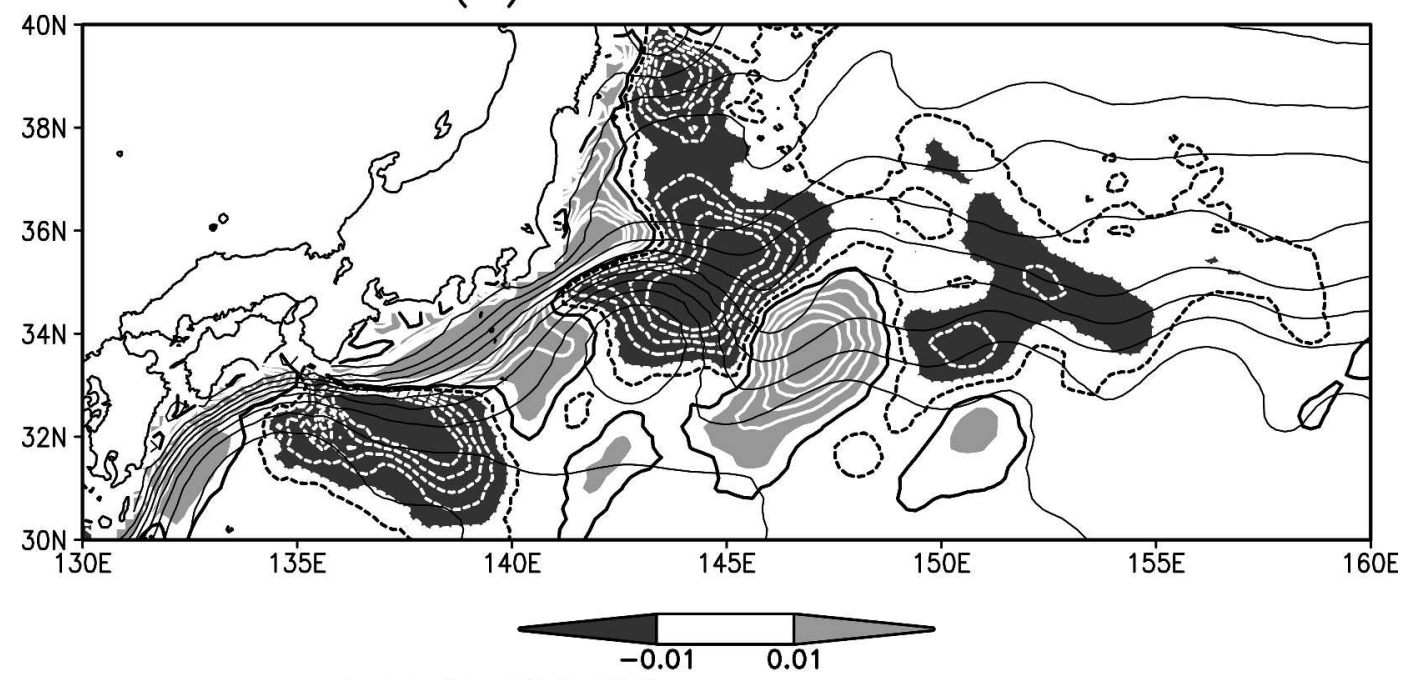

- - : $-d\left\langle u^{\prime} u^{\prime}>/ d x\right.$ 142.5-163E

$\cdots \cdot:-d\left\langle u^{\prime} v^{\prime}\right\rangle / d y \quad 142.5-163 E$

(b) control

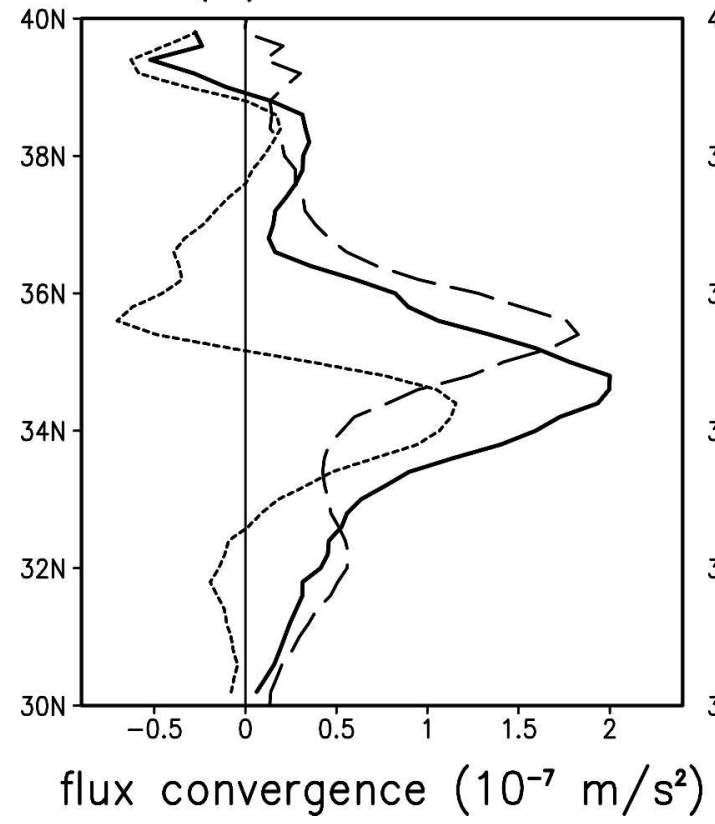

(c) forced-control

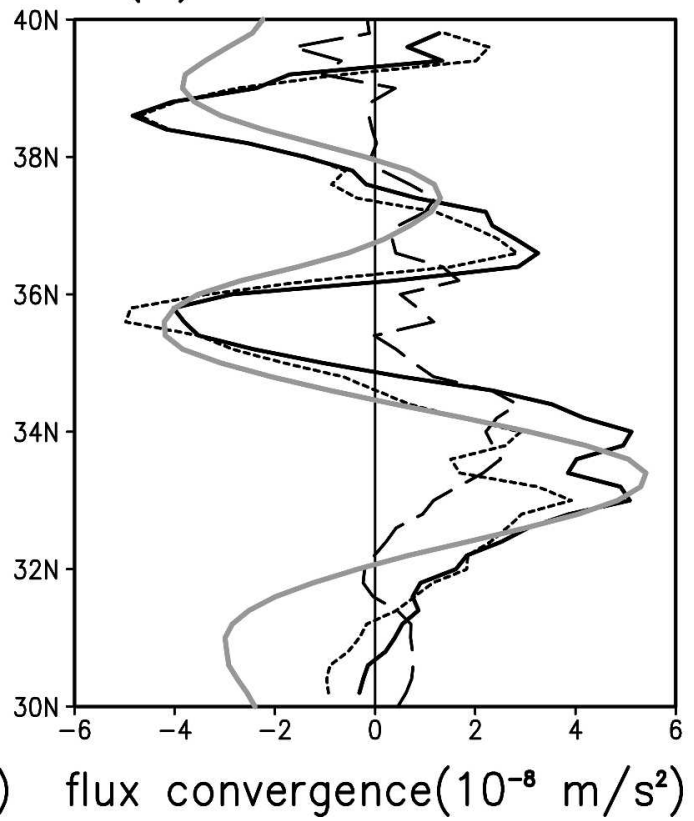

FIG. 13. (a) Reynolds stress $\left\langle u^{\prime} v^{\prime}\right\rangle$ at 50-m depth (shading) and mean SSH (contour) in the control run. Eddy components of current velocity are defined with respect to the ensemble and monthly mean climatology. The bracket designates ensemble and temporal mean for the last $5 \mathrm{yr}$ of the integrations. (b) Zonal mean of the Reynolds stress convergence averaged over $142.5^{\circ}-163^{\circ} \mathrm{E}$ in the control run. The dashed and dotted lines are variance and covariance components, respectively, and the solid line shows their summation. (c) As in (b), but for the difference between the forced run and the control run. The zonal current velocity at 50-m depth averaged over $142.5^{\circ}-163^{\circ} \mathrm{E}$ (solid line in Fig. $6 \mathrm{~d}$ ) is redrawn for reference. 
For example, several modeling studies have shown that the atmospheric response to increased greenhouse gases and orbital-induced changes in solar radiation is organized into annular mode-like patterns, with narrow anomalous zonal jets (Hall et al. 2005 and references therein) as a result of wave-mean flow interaction (Jin et al. 2004, manuscript submitted to J. Atmos. Sci.).

\section{Summary}

The KE's response to large-scale Rossby waves excited by the anomalous lateral forcing is studied using a high-resolution regional OGCM, with an ultimate goal of understanding the KE variations following the 1976/ 77 regime shift. After lateral forcing is imposed at the model's eastern boundary, baroclinic Rossby waves emanate from the boundary and propagate westward at phase speeds comparable to those derived from satellite altimetry observations (Qiu 2003; Fu and Chelton 2001). In the steady state, the KE intensifies, leaving a narrow anomalous eastward jet of a meridional width much smaller than that of the lateral forcing. The narrow acceleration and a slight southward shift of the KE are broadly consistent with historical observations of the 1970s climate regime shift (Deser et al. 1999; Joyce and Dunworth-Baker 2003). Associated with the KE acceleration is an increase in the wavelengths of $\mathrm{KE}$ quasi-stationary meanders, a response consistent with the stationary Rossby wave theory. The transient eddy activity is also visibly elevated, and the momentum flux associated with these eddies is to strengthen the mean flow response.

The linear Sverdrup theory does not explain the narrow acceleration of the KE current. The KE acceleration is associated with enhanced PV gradients across the KE front with decreased PV to the south. This PV adjustment seems consistent with inertial western boundary current theory: as Rossby waves arrive at the western boundary, the resultant broad acceleration of the eastward current increases the advection of low PV water of subtropical origin via the western boundary layer, lowering the PV south of the KE. The negative $\mathrm{PV}$ anomalies result in the spinup of an anticyclonic recirculation and a narrow eastward jet on its northern flank. Results from a simple QG model experiment demonstrate this inertial mechanism, displaying a narrow eastward acceleration between a pair of spunup recirculations that encircle significant PV anomalies.

Decadal/interdecadal swings of North Pacific winds take broad scales in the meridional direction, scales determined by planetary-scale atmospheric dynamics. Our study suggests that, in response to this broad wind forcing, major physical changes of the western North Pacific, in current velocity, temperature, and salinity, take place on a much narrower meridional scale along the KE front. Analysis of a multidecadal hindcast using a $0.1^{\circ}$ high-resolution global OGCM seems to confirm this result (M. Nonaka 2004, personal communication). Major mode waters form in the KE region (Suga et al. 1997), which may play an important role in the dynamical response to decadal wind forcing in the subtropical gyre through changes in their paths (Kubokawa and Xie 2002; Hosoda et al. 2004). It remains to be seen how important the remotely forced KE response is compared to changes in local fluxes for mode water variability. The KE front is a region of great importance for fisheries (Noto and Yasuda 1999), and the fishery implications of the meridional confinement of physical changes to ocean fronts need to be studied.

Acknowledgments. The authors wish to thank M. Nonaka, B. Qiu, and T. Waseda for useful discussion; F. Kobashi for allowing us his recursive-type high-pass filter; and R. B. Scott and an anonymous reviewer for their constructive suggestions. This research is supported by JAMSTEC.

\section{APPENDIX}

\section{The QG Model}

The model used in section 5a is a three-layer quasigeostorophic model with the following governing equations:

$$
\begin{aligned}
& {\left[\frac{\partial}{\partial t}+\frac{\partial \Psi_{j}}{\partial x} \frac{\partial}{\partial y}-\frac{\partial \Psi j}{\partial y} \frac{\partial}{\partial x}\right]} \\
& \left\{\nabla^{2} \Psi_{j}-\frac{f_{0}^{2}}{g^{\prime} H_{j}}\left(2 \Psi_{j}-\Psi_{j-1}-\Psi_{j+1}\right)\right\}+\beta \frac{\partial \Psi_{j}}{\partial x} \\
& =\delta_{1, j} \frac{f_{0} w_{e}}{H_{1}}+\nu \nabla^{2}\left(\nabla^{2} \Psi j\right) U,
\end{aligned}
$$

where $t$ is the time, $x$ and $y$ are the eastward and northward coordinates, respectively, $\nabla$ is the horizontal differential operator, $\Psi_{j}$ is the streamfunction in the $j$ th layer $(j=1,2,3)$, with $\Psi_{0}=\Psi_{1}$ and $\Psi_{4}=\Psi_{3}, \delta_{i, j}$ is the Kroneker delta, $H_{j}$ is the thicknesses of the $j$ th layer, and $g^{\prime}$ is the reduced gravity. The layer thicknesses are chosen as $H_{1}=200, H_{2}=400$, and $H_{3}=4400 \mathrm{~m}$. The reduced gravity is chosen as $g^{\prime}=0.15 \mathrm{~m} \mathrm{~s}^{-2}$, which gives a Rossby radius of deformation for the first baroclinic mode $\lambda_{1}=50 \mathrm{~km}$ at $35^{\circ} \mathrm{N}$ with the layer depths given above.

The QG model has a rectangular basin of $2.5 \mathrm{~L} \times 2 \mathrm{~L}$ in longitude and latitude $(L=1500 \mathrm{~km})$. The model 
uses the Laplacian-type diffusion [Eq. (A1)] with the eddy viscosity $\nu=540 \mathrm{~m} \mathrm{~s}^{-2}$. Nonslip condition is applied for lateral boundaries. The grid size is chosen to be $\Delta x=L / 100=15 \mathrm{~km}$, and there are two grid points in the Munk viscous layer, $\delta_{m}=\sqrt{\nu / \beta}$. The time for the first baroclinic-mode long Rossby wave to cross the basin is given by $\tau=2.5 \mathrm{~L} / \mathrm{c} \sim 2.38 \mathrm{yr}$, where $c=\beta \lambda_{1}^{2}$ is the phase speed.

\section{REFERENCES}

Blumberg, A. F., and G. L. Mellor, 1983: Diagnostic and prognostic numerical circulation studies of the South Atlantic Bight. J. Geophys. Res., 88, 4579-4592.

Cessi, P. R., G. Ierley, and W. R. Young, 1987: A model of inertial recirculation driven by potential vorticity anomalies. J. Phys. Oceanogr., 17, 1640-1652.

Deser, C., M. A. Alexander, and M. S. Timlin, 1999: Evidence for a wind-driven intensification of the Kuroshio Current extension from the 1970s to the 1980s. J. Climate, 12, 1697-1706.

Ducet, N., and P.-Y. LeTraon, 2001: A comparison of surface eddy kinetic energy and Reynolds stress in the Gulf Stream and the Kuroshio current system from merged TOPEX/ Poseidon and ERS-1/2 altimetric data. J. Geophys. Res., 106, 16 603-16 662.

Ebuchi, N., and K. Hanawa, 2000: Mesoscale eddies observed by TOLEX-ADCP and TOPEX/POSEIDON altimeter in the Kuroshio recirculation region south of Japan. J. Oceanogr., 56, 43-57.

Fofonoff, N. P., 1954: Steady flow in a frictionless homegeneous ocean. J. Mar. Res., 13, 254-262.

Fu, L.-L., and D. B. Chelton, 2001: Large-scale ocean circulation. Satellite Altimetry and Earth Science, L.-L. Fu and A. Cazenava, Eds., Academic Press, 133-169.

Gille, S., 1997: Why potential vorticity is not conserved along mean streamlines in a numerical Southern Ocean. J. Phys. Oceanogr., 27, 1286-1299.

Hall, A., A. Clement, D. W. J. Thompson, A. Broccoli, and C. Jackson, 2005: The importance of atmospheric dynamics in the Northern Hemisphere wintertime climate response to changes in the earth's orbit. J. Climate, 18, 1315-1325.

Hellerman, S., and M. Rosenstein, 1983: Normal wind stress over the world ocean with error estimates. J. Phys. Oceanogr., 13, 1093-1104.

Holland, W. R., T. Keffer, and P. B. Rhines, 1984: Dynamics of the oceanic general circulation: The potential vorticity field. Nature, 308, 698-705.

Hosoda, S., S.-P. Xie, K. Takeuchi, and M. Nonaka, 2004: Interdecadal temperature variations in the North Pacific central mode water simulated by an OGCM. J. Oceanogr., 60, 865877.

Joyce, T. M., and J. Dunworth-Baker, 2003: Long-term hydrographic variability in the Northwest Pacific Ocean. Geophys. Res. Lett., 30, 1043, doi:10.1029/2002GL015225.

Kawabe, M., 1995: Variations of current path, velocity, and volume transport of the Kuroshio in relation with the large meander. J. Phys. Oceanogr., 25, 3103-3117.

Kubokawa, A., and S.-P. Xie, 2002: On steady response of a ventilated thermocline to enhanced Ekman pumping. J. Oceanogr., 58, 565-575.
Levitus, S., 1982: Climatogical Atlas of the World Ocean. NOAA Prof. Paper 13, 173 pp. and 17 microfiche.

Miller, A. J., D. R. Cayan, and W. B. White, 1998: A westwardintensified decadal change in the North Pacific thermocline and gyre-scale circulation. J. Climate, 11, 3112-3127.

Mitsudera, H., T. Waseda, Y. Yoshikawa, and B. Taguchi, 2001: Anticyclonic eddies and Kuroshio meander formation. Geophys. Res. Lett., 28, 2025-2028.

_ B. Taguchi, Y. Yoshikawa, H. Nakamura, T. Waseda, and T. Qu, 2004: Numerical study on the Oyashio water pathways in the Kuroshio-Oyashio confluence. J. Phys. Oceanogr., 34, 1174-1196.

Mizuno, K., and W. B. White, 1983: Annual and interannual variability in the Kuroshio Current System. J. Phys. Oceanogr., 13, 1847-1867.

Nakamura, H., and A.S. Kazmin, 2003: Decadal change in the North Pacific oceanic frontal zones as revealed in ship and satellite observations. J. Geophys. Res., 108, 3078, doi:10. 1029/1999JC000085.

_ G. Lin, and T. Yamagata, 1997: Decadal climate variability in the North Pacific during recent decades. Bull. Amer. Meteor. Soc., 78, 2215-2225.

_, T. Sampe, Y. Tanimoto, and A. Shimpo, 2004: Observed associations among storm tracks, jet streams, and midlatitude oceanic fronts. Earth Climate: The Ocean-Atmosphere Interaction, Geophys. Monogr., No. 147, Amer. Geophys. Union, 329-345.

Nakamura, M., and Y. Chao, 2001: Diagnosis of an eddy-resolving Atlantic Ocean model simulation in the vicinity of the Gulf Stream. Part I: Potential vorticity. J. Phys. Oceanogr., 31, 353-378.

Niiler, P. P., N. A. Maximenko, G. G. Panteleev, T. Yamagata, and D. B. Olson, 2003: Near-surface dynamical structure of the Kuroshio Extension. J. Geophys. Res., 108, 3193, doi:10.1029/2002JC001461.

Nonaka, M., and S.-P. Xie, 2003: Covariations of sea surface temperature and wind over the Kuroshio and its extension: Evidence for ocean-to-atmospheric feedback. J. Climate, 16, 1404-1413.

Noto, M., and I. Yasuda, 1999: Population decline of the Japanese sardine in relation to the sea-surface temperature in the Kuroshio Extension. Can. J. Fish. Aquat. Sci., 56, 973-983.

Qiu, B., 2000: Interannual variability of the Kuroshio Extension system and its impact on the wintertime SST field. J. Phys. Oceanogr., 30, 1486-1502.

— , 2002: The Kuroshio extension system: Its large-scale variability and role in the midlatitude ocean-atmosphere interaction. J. Oceanogr, 58, 57-75.

_ 2003: Kuroshio Extension variability and forcing of the Pacific decadal oscillations: Responses and potential feedback. J. Phys. Oceanogr., 33, 2465-2482.

Qu, T., H. Mitsudera, and B. Qiu, 2001: A climatological view of the Kuroshio/Oyashio system east of Japan. J. Phys. Oceanogr., 31, 2575-2589.

Rothstein, L. M., R.-H. Zhang, A. J. Busalacchi, and D. Chen, 1998: A numerical simulation of the mean water pathways in the subtropical and tropical Pacific Ocean. J. Phys. Oceanogr., 28, 322-343.

Schneider, N., and A. J. Miller, 2001: Predicting western North Pacific ocean climate. J. Climate, 14, 3997-4002. 
, and D. W. Pierce, 2002: Anatomy of North Pacific decadal variability. J. Climate, 15, 586-605.

Scott, R. B., and B. Qiu, 2003: Predictability of SST in a stochastic climate model and its application to the Kuroshio Extension region. J. Climate, 16, 312-322.

Seager, R., Y. Kushnir, N. H. Naik, M. A. Cane, and J. Miller, 2001: Wind-driven shifts in the latitude of the KuroshioOyashio Extension and generation of SST anomalies on decadal timescales. J. Climate, 14, 4249-4265.

Slutz, R. J., S. J. Lubker, J. D. Hiscox, S. D. Woodfuff, R. L. Jenne, D. H. Joseph, P. M. Steurer, and J. D. Elms, 1985: Comprehensive Ocean-Atmosphere Data Set: Release 1. Tech. Rep., NOAA/Environmental Research Laboratory, 268 pp.

Suga, T., Y. Takei, and K. Hanawa, 1997: Thermostad distribution in the North Pacific subtropical gyre: The central mode water and the subtropical mode water. J. Phys. Oceanogr., 27, 140152.

Sugimoto, T., S. Kimura, and K. Tadokoro, 2001: Impact of El Niño events and climate regime shift on living resources in the western North Pacific. Progress in Oceanography, Vol. 49, Pergamon, 113-127.

Tai, C.-K., and W. B. White, 1990: Eddy variability in the Kuro- shio Extension as revealed by GEOSAT altimetry: Energy propagation away from the jet, Reynolds stress, and seasonal cycle. J. Phys. Oceanogr., 20, 1761-1777.

Tanimoto, Y., H. Nakamura, T. Kagimoto, and S. Yamane, 2003: An active role of extratropical sea surface anomalies in determoning turbulent heat fluxes. J. Geophys. Res., 108, 3304, doi:10.1029/2002JC001750.

Tomita, T., S.-P. Xie, and M. Nonaka, 2002: Estimates of surface and subsurface forcing for decadal sea surface temperature variability in the mid-latitude North Pacific. J. Meteor. Soc. Japan, 80, 1289-1300.

Waseda, T., H. Mitsudera, B. Taguchi, and Y. Yoshikawa, 2002: On the eddy-Kuroshio interaction: Evolution of the mesoscale eddy. J. Geophys. Res., 107, 3088, doi:10.1029/ 2000JC000756.

,,--- , and,- 2003 : On the eddy-Kuroshio interaction: Meander formation process. J. Geophys. Res., 108, 3220, doi:10.1029/2002JC001583.

Xie, S.-P., T. Kunitani, A. Kubokawa, M. Nonaka, and S. Hosoda, 2000: Interdecadal thermocline variability in the North $\mathrm{Pa}$ cific for 1958-1997: A GCM simulation. J. Phys. Oceanogr., 30, 2798-2813. 